\title{
A importância do programa Ciência sem Fronteiras: o estudo do caso australiano, primeiros resultados e recomendações
}

The importance of the Ciência sem Fronteiras program: the Australian case, first results and recommendations

\section{La importancia del programa Ciência sem Fronteiras: estudio del caso australiano, primeros resultados y recomendaciones}

http://dx.doi.org/10.21713/2358-2332.2016.v13.955

Dileine Amaral da Cunha, doutoranda em Educação em Ciência pela Universidade Federal do Rio Grande do Sul (UFRGS) e analista em ciência e tecnologia do Conselho Nacional de Desenvolvimento Científico e Tecnológico (CNPq), Brasília, DF, Brasil. E-mail: dileinecunha@hotmail.com.

Ivan Rocha Neto, doutor em Eletrônica pela University of Kent, Canterbury, Reino Unido, e professor colaborador da Universidade Federal do Rio Grande do Sul (UFRGS), Brasília, DF, Brasil. E-mail: neto-ivan@hotmail.com.

\section{Resumo}

O texto apresentado a seguir mostra a importância do programa Ciência sem Fronteiras no processo de internacionalização da educação superior brasileira, com base em estudo de caso da Austrália. Esse país acolheu em suas universidades vários estudantes brasileiros contemplados com bolsas de estudo. A metodologia envolveu pesquisa documental e bibliográfica, incluindo consulta aos documentos dos organismos internacionais e dos governos australiano e brasileiro. Os resultados obtidos foram discutidos considerando-se o relatório final de avaliação elaborado pela Comissão de Ciência, Tecnologia, Inovação, 
Comunicação e Informática do Senado Federal, bem como alguns artigos de análise crítica do programa.

Palavras-chave: Educação Superior. Internacionalização. Programa Ciência sem Fronteiras.

\section{Abstract}

The text below shows the importance of the Ciência sem Fronteiras program in the Brazilian higher education internationalization process, based on the case study of Australia. That country hosted in its universities several Brazilian students who were awarded with scholarships. The methodology involved documentary and bibliographic research, including consultation of documents prepared by international organizations and the Australian and Brazilian governments. The results obtained were discussed considering the evaluation final report prepared by the Commission of Science, Technology, Innovation, Communication and Informatics of the Federal Senate, as well as some articles of critical analysis of the program.

Keywords: Higher Education. Internationalization. Ciência sem Fronteiras Program.

\section{Resumen}

El texto presentado muestra la importancia del programa Ciência sem Fronteiras en el proceso de internacionalización de la educación superior brasileña, basado en el estudio de caso de Australia. Este país recibió en sus universidades varios estudiantes brasileños becados. La metodología abarcó investigación documental y bibliográfica, incluyendo consulta a documentos de organismos internacionales y de los gobiernos australiano y brasileño. Los resultados se discutieron teniendo en cuenta el informe final de evaluación realizada por la Comisión de Ciencia, Tecnología, Innovación, Comunicación e Informática del Senado Federal, así como algunos artículos de análisis crítico del programa.

Palabras clave: Educación Superior. Internacionalización. Programa Ciência sem Fronteiras. 


\section{INTRODUÇÃO}

Na economia do conhecimento, o crescimento econômico e o desenvolvimento passam a depender mais das habilidades e dos produtos intelectuais. Meek (2004, p. 1025), referindo-se ao caso australiano, afirma que "o crescimento econômico da Austrália será cada vez mais vinculado à beca e menos à lã de carneiro [...]”. São os novos desafios, assim postulados por Rocha Neto (2010, p. 59), que a educação superior e o Sistema Nacional de Pós-Graduação (SNPG) são chamados a enfrentar.

A partir do $4^{\circ}$ Plano Nacional de Pós-Graduação (PNPG), da década de 1990 em diante, o Brasil passou a tratar a internacionalização da pós-graduação como uma das metas centrais. O país sempre esteve atento às recomendações postuladas pelos organismos internacionais, que funcionam como embaixadores das nações centrais, no sentido de trazer, seja por meio de estatísticas, seja por meio de relatórios, o panorama da educação mundial. Documentos como o Education at a Glance, publicado anualmente pela Organização para a Cooperação e Desenvolvimento Econômico (OCDE), e as estatísticas do Instituto de Estatística da Organização das Nações Unidas para a Educação, a Ciência e a Cultura (Unesco), são fontes de análise e de influências.

O PNPG 2011-2020 reforça essa política ao priorizar a atração de pesquisadores e docentes estrangeiros e o envio de estudantes de doutorado pleno e pós-doutorado para períodos de formação no exterior, como forma de capacitação e transferência de conhecimento (CAPES, 2010, p. 22). Apesar de o SNPG estar consolidado e possuir status de política pública, há pouquíssimos estudantes e docentes estrangeiros no Brasil, como também há poucos estudantes brasileiros de doutorado em outros países, notadamente em áreas prioritárias, como as Engenharias. Nas melhores universidades do mundo, incluindo as australianas, aproximadamente $20 \%$ dos estudantes são estrangeiros.

O programa Ciência sem Fronteiras (CsF), instituído por meio do Decreto $n^{\circ}$ 7.642, de 13 de dezembro de 2011, se inscreve nesse contexto, ou seja, o da necessidade de colocar o país em circuito internacional e, 
dessa forma, reduzir o atraso na área científica e tecnológica. Como postulado por Spears (2014), o programa é "um produto da economia global e nacional e resultado de uma era da informação tecnologicamente orientada”, que projeta o Brasil internacionalmente, como potencial econômico, em prol do desenvolvimento nacional.

O lançamento oficial do programa ocorreu em 26 de julho de 2011, na ocasião da 38 a Reunião Ordinária do Pleno do Conselho de Desenvolvimento Econômico e Social (CDES), pelo então Ministro da Ciência, Tecnologia e Inovação, Aloízio Mercadante (AVEIRO, 2014, p. 2). Entre os presentes, representantes do setor privado, responsável pelo aporte financeiro de 26 mil bolsas. 0 governo federal assumiu as demais 75 mil bolsas, ao custo, até 2015, de R $\$$ 10,5 bilhões (BRASIL, 2015b, p. 33).

Anseios de interesse nacional apontavam que, apesar de a ciência brasileira ter avançado muito nos últimos anos, ainda não alcançou o suficiente para posicionar o Brasil no patamar de desenvolvimento em que se encontram outros membros do BRICS (agrupamento de países para a cooperação econômica, formado por Brasil, Rússia, Índia, China e África do Sul), como Rússia e China, além da Coreia do Sul. Nesse sentido, a criação do CsF foi parte da Estratégia Nacional de Ciência, Tecnologia e Inovação do primeiro governo de Dilma Rousseff.

Segundo a Estratégia Nacional de Ciência, Tecnologia e Inovação 2012-2015 - Balanço das Atividades Estruturantes:

O programa Ciência sem Fronteiras (CsF) tem o objetivo geral de promover de maneira acelerada o desenvolvimento tecnológico e estimular os processos de inovação no Brasil por meio da qualificação de estudantes [...] em áreas consideradas prioritárias e estratégicas para o desenvolvimento do País. Complementarmente, visa promover a cooperação técnico-científica entre pesquisadores brasileiros e pesquisadores de reconhecida liderança científica residentes no exterior por meio de Programas Bilaterais e Programa para fixação parcial no País [...] (BRASIL, 2012, p. 18, grifo nosso).

Sobre as áreas estratégicas, apesar de apontarem a importância das Ciências Sociais e Humanas, Castro et al. (2012, p. 33) salientam que 
as deficiências do Brasil em STEM, usando a abreviação em inglês para Science, Technology, Engineering and Maths, de fato existem. Segundo o PNPG 2011-2020, a formação de doutores em Humanidades, Ciências Biológicas e Saúde é consideravelmente maior do que nas Engenharias e isto deve ser mudado, "seja para atender as novas prioridades e ênfases do Plano, seja para fazer face aos desafios e gargalos, sob pena da inviabilização da Agenda Nacional da Pesquisa” (CAPES, 2010, p. 20).

A gestão do novo programa é de responsabilidade do Ministério da Educação (MEC) e do Ministério da Ciência, Tecnologia e Inovação (MCTI), com suas respectivas agências de fomento, a Coordenação de Aperfeiçoamento de Pessoal de Nivel Superior (Capes) e o Conselho Nacional de Desenvolvimento Cientifico e Tecnológico (CNPq). Essas agências, que desde a implantação do programa em 2011 ampliaram a concessão de bolsas ao exterior para além de 10 vezes, são responsáveis pelo lançamento das chamadas públicas, seleção e acompanhamento. Há ainda o Comitê de Acompanhamento e Assessoramento e o Comitê Executivo, que auxiliam na governança das ações.

Apesar da sólida experiência das agências referidas em formação de recursos humanos, fomento à pesquisa no exterior, parcerias internacionais com agências congêneres e seleção por mérito, a dimensão e a ousadia do programa, juntamente com as pressões do governo federal, levaram à adequação dos processos dos setores internos envolvidos, sobretudo na área internacional e de informática. Foram necessários, por exemplo, ajustes para que as agências trabalhassem de forma conjunta, a transferência de técnicos das áreas fins para se dedicarem ao programa e a adequação da infraestrutura.

Do total de 101 mil bolsas previstas, a maioria (73\%) foi destinada ao fomento da graduação sanduíche no exterior (CNPq, 2016). Nessa nova modalidade, o estudante pode fazer até dois semestres acadêmicos em outro país. O contato mais cedo com centros de excelência e de pesquisa no exterior visa ao aperfeiçoamento tanto do estudante quanto da instituição de ensino superior (IES). Visa ainda motivar o estudante a dar continuidade aos estudos no Brasil e no exterior. 
Nas palavras de Pereira (2015, p. 109), a inclusão da graduação no programa de mobilidade internacional cria "condições para a popularização da ciência e para a melhoria da educação superior brasileira, uma vez que os estudantes retornam com novas ideias [...]". Afinal, ao retornarem da mobilidade acadêmica, após contato com novas metodologias e currículos, os estudantes, podem trazer inovações passiveis de serem adaptadas e internalizadas pelas instituições brasileiras.

Nesses termos, o presente artigo tem o propósito de examinar a relevância do programa Ciência sem Fronteiras no processo de internacionalização da educação superior brasileira e a necessidade de sua continuidade como política pública, tomando como referência um estudo de caso em que são os bolsistas enviados para a Austrália. Acrescenta-se que a análise da experiência de internacionalização com a cooperação de instituições de pesquisa australianas é feita considerando a avaliação levada a efeito pela Comissão de Ciência, Tecnologia, Inovação, Comunicação e Informática (CCT) do Senado Federal e algumas críticas que têm sido feitas ao programa.

\section{MATERIAL E MÉTODO}

A metodologia envolveu pesquisa quali-quantitativa, análise documental e bibliográfica atual sobre o tema, incluindo livros, artigos, dissertações e teses, relatórios e papers, bem como a análise de dados estatísticos. A riqueza de contribuições que encapsulam um fato novo na história recente da educação superior brasileira e o impacto que a mobilidade acadêmica causa no processo de internacionalização e na economia do conhecimento geram uma produção de bibliografia rica em dados informativos, a exemplo dos relatórios da Unesco e do Banco Mundial, além de publicações dos governos brasileiro e australiano, amplamente consultadas para esta pesquisa. 


\section{O PAPEL DO PROGRAMA CIÊNCIA SEM FRONTEIRAS NA INTERNACIONALIZAÇÃO DA EDUCAÇÃO SUPERIOR BRASILEIRA}

O conceito de internacionalização ativa e passiva no campo da educação superior está presente na revisão de literatura sobre o tema, em especial nas publicações mais recentes, datadas do início do século XXI. Lima e Maranhão (2009, p. 585) afirmam que o termo “ativo" possui sentido positivo, uma vez que se refere a quem pratica uma ação e, portanto, tende a dominar, enquanto o termo "passivo" é negativo e está relacionado a quem é objeto da ação. Acrescenta-se que as nações do mundo estão divididas em três categorias: centrais, semiperiféricas e periféricas (WALLERSTEIN, 1976 apud LIMA; CONTEL, 2011, p. 363).

As nações centrais são as mais fortes e desenvolvidas, tanto política como economicamente, exportadoras de tecnologia e inovação, além de sediarem empresas transnacionais. As nações semiperiféricas têm o Estado como protagonista e financiador do desenvolvimento econômico e são responsáveis pelo equilíbrio do sistema mundial, uma vez que exploram as nações periféricas, ao mesmo tempo em que são exploradas pelas nações centrais. As nações periféricas são as mais pobres, sem capacidade de consumo, com uma economia pouco desenvolvida e baseada, na maioria das vezes, no setor primário.

Na análise do fluxo global de estudantes no ensino superior, proporcionada pelo Instituto de Estatística da Unesco (2016), as nações mais desenvolvidas e hegemônicas são também as que mais recebem estudantes internacionais. Dados de 2013 apontam que países como Estados Unidos, Reino Unido, Austrália, França e Alemanha receberam metade dos 4,1 milhões de estudantes em mobilidade internacional. Esses países possuem políticas consolidadas voltadas à internacionalização da educação superior, com algumas exceções. Além do 100,000 Strong in the Americas, dos Estados Unidos, a União Europeia tem o programa Erasmus, inaugurado em 1987 para promover a mobilidade estudantil e a cooperação entre os países da Europa.

Knight (2005, p. 21-22 apud LIMA; MARANHÃO, 2009, p. 585) salienta que a internacionalização da educação superior vai além da 
mobilidade de estudantes, professores e pesquisadores, porque passa a envolver a "circulação de programas, abertura de campi e instalação de instituições fora do país de origem". São inúmeros os benefícios da mobilidade internacional no processo de internacionalização, sendo o fortalecimento das redes de pesquisa um deles. Nesse sentido, "há pesquisa empírica para sugerir que essas redes servem como canais para o fluxo de conhecimento global em contextos locais" (MERLE; MEEK, 2013, p. 339, tradução nossa). No Brasil, a formação de redes de cooperação científica pode representar maiores ganhos para as instituições localizadas fora do centro (ROCHA NETO, 2010, p. 60).

O movimento do Sul em direção ao Norte, do periférico e semiperiférico em direção ao centro, predominante nos processos de internacionalização e mobilidade acadêmica é um exemplo de soft power. O movimento está relacionado à sociedade do conhecimento, à globalização e à competição inerente ao processo, em que é preciso competir para se ter status global (MURRAY et al., 2011). O termo soft poweré um empréstimo da teoria das relações internacionais, postulado por Joseph Nye e Robert Keohane (2001), ao se referirem a fenômenos da era neoliberal.

Trata-se da influência que algumas nações, em geral com boa reputação internacional, exercem sobre as outras, sem a necessidade do uso da força ou da coerção (hard power). Ao contrário, o soft power ocorre quando um país consegue fazer com que outros países adotem e concordem com seus valores culturais, intelectuais etc. (KEOHANE; NYE, 2001, p. 221-224). Daí a importância de uma estratégia de internacionalização que efetivamente contribua para o avanço da ciência e da tecnologia em perspectiva de desenvolvimento sustentado.

Dessa forma, o CsF é um marco no sentido de projetar o Brasil internacionalmente, além de colaborar em larga escala com o processo de internacionalização das universidades brasileiras. Estudiosos passaram a incluir o Brasil no rol dos países em desenvolvimento que financiam programas específicos de internacionalização. Merle e Meek afirmam que, “[...] pelo menos no caso brasileiro, o foco é em ter cientistas e jovens pesquisadores por uma temporada no exterior" (2013, p. 335, tradução nossa). 
Os destinos preferidos dos estudantes brasileiros são: Estados Unidos, Portugal, França, Alemanha e Reino Unido (UNESCO/UIS, 2016), ficando a Austrália na sétima posição depois da Espanha. No CsF, os países que mais receberam estudantes foram Estados Unidos, Reino Unido, Canadá, França e Austrália. Registre-se que a Austrália tem sido um referencial na recepção de estudantes internacionais.

O programa de mobilidade brasileiro tem influenciado positivamente os trabalhos desenvolvidos pela Associação Brasileira de Educação Internacional (Faubai). Muitas universidades que ainda não tinham escritório de relações internacionais passaram a ter, com vistas a tratar da internacionalização de forma institucionalizada. Nas palavras de Castro et al. (2012, p. 35):

[...] o programa Ciência sem Fronteiras pode significar uma virada importante para a educação superior e a ciência e tecnologia do país. Ele rompe com um certo provincianismo que parecia ter se acentuado no setor, nos últimos anos, e confirma a vocação do país em ter uma participação cada vez maior, mais competente e mais competitiva no mundo atual, onde os conhecimentos de alto nível são o fator mais escasso.

As exigências do processo seletivo do CsF provocaram uma corrida pelo domínio de idioma estrangeiro. Ainda nos primeiros editais em 2012, percebeu-se que o Brasil era um país monoglota. A recente revisão crítica publicada na revista Ensino Superior confirma este fato, ao afirmar que o CsF mostrou que o Brasil possui “pouco domínio [...] de comunicação em outros idiomas, o que por muitos anos vem deixando o país à parte das discussões mais importantes em diferentes áreas" (STALLIVIERI, 2016). A criação do projeto Idiomas sem Fronteiras (IsF) veio, em parte, preencher essa lacuna. Trata-se de uma iniciativa do MEC-Capes, para o incentivo do ensino de línguas estrangeiras nas universidades brasileiras. O projeto viabiliza a participação de estudantes no CsF e em outros programas de mobilidade internacional. 


\section{PROGRAMA CIÊNCIA SEM FRONTEIRAS NA AUSTRÁLIA: DESENVOLVIMENTO E RESULTADOS}

A Austrália possui seis estados e dois territórios, sendo a governança da educação compartilhada nas esferas federal, estadual e territorial. A educação internacional é um dos maiores serviços de exportação, tendo injetado 16,3 bilhões de dólares australianos na economia do país entre 2013 e 2014 (AUSTRALIA, 2014). A educação superior é responsável por 68\% desse montante. De acordo com o Country Education Profiles (2015a), a Austrália possui 43 universidades multidisciplinares, sendo 37 instituições públicas, três particulares, uma de especialização e duas estrangeiras, que possuem autonomia para definir currículos, carga horária, estrutura e orçamento.

A convivência multicultural ativa é importante para a construção de parcerias duradouras, capazes de movimentar a economia e mostrar a Austrália para o mundo, como sendo um provedor de educação de classe mundial. Os principais parceiros, no que tange a publicações conjuntas, são os estadunidenses, os britânicos e os chineses. Contudo, a expansão é necessária e, neste sentido, a América Latina é região estratégica nas políticas de internacionalização do país.O ensino superior é parte da política pública intitulada Australian Qualifications Framework(AQF), cuja estrutura taxonômica de níveis e tipos de títulos incorpora a qualificação de cada setor da educação, da escola primária à universidade e, ainda, à formação profissional. A flexibilidade da estrutura permite alinhamento entre os diversos níveis, sendo que um nível pode ter mais de um tipo de qualificação.

A avaliação da educação superior é feita pela Tertiary Education Quality and Standards Agency (TEQSA), com base no Higher Education Standards Framework. Com regime estatutário independente e membros nomeados pelo Ministro da Educação, a agência é responsável pelo credenciamento e recredenciamento de cursos e instituições de ensino superior. Esse sistema complexo de avaliação é resultado da revisão do ensino superior idealizada pelo governo australiano em 2008 e conduzida por um grupo de especialistas independentes. 0 trabalho resultou no relatório conhecido como Bradley Review (BRADLEY et al., 2008). 
Os estudantes internacionais estão sob a égide do The Education Services for Overseas Students Act 2000 (ESOS Act), o qual garante a oferta de ensino de alta qualidade compatível com os valores de anuidades cobrados. Ademais, o documento contendo as políticas de internacionalização, o Draft Nationa/ Strategy for International Education (AUSTRALIA, 2015b), foi publicado como rascunho de consulta em 2015. A redação final deverá atender plenamente às expectativas e demandas do país.

Apesar de os estudantes arcarem com os custos da educação superior, há investimento público nas instituições de ensino e pesquisa, cujos valores podem variar de acordo com o processo de avaliação. As contribuições e as formas de pagamento e financiamentos disponíveis dependem do tipo de estudante e de instituição de ensino, e tanto podem ser pelo Commonwealth Grant Scheme tanto pelos chamados fee-paying (AUSTRALIA, 2015a, p. 19). Estas ações fazem parte do conjunto de recomendações postuladas pelo Banco Mundial (1994), em Higher Education: The Lessons of Experience. É interessante notar que:

Foi um governo trabalhista que, no fim dos anos 1980, acabou introduzindo essa tendência de maior diversificação do financiamento da educação superior australiana. $O$ atual governo de coalizão liberal, que chegou ao poder em 1995, acelerou essa tendência reduzindo, em termos reais, a participação financeira direta da União na educação superior e aumentando substancialmente o ônus financeiro assumido pelos alunos. (MEEK, 2004, p. 1026).

Nesse trecho Meek (2004) se refere ao primeiro-ministro australiano do partido liberal, John Howard, que deu continuidade ao processo de redução do financiamento público à educação superior, iniciado por Bob Hawke, do partido trabalhista, na década de 1980. Todavia, em 2007, Howard cedeu lugar ao partido trabalhista novamente e, apesar da alternância de ideologias, as políticas educacionais não foram modificadas. Meek (2002, p. 159), citado por Sguissardi (2002, p. 13), confirma a afirmação e complementa informando que os últimos líderes australianos têm priorizado a competição, as relações de mercado e a privatização nas ações relacionadas ao ensino superior. 
A Austrália tem o segundo melhor Índice de Desenvolvimento Humano (IDH) do mundo e universidades bem conceituadas internacionalmente. Segundo o ranking QS Top Universities, Melbourne e Sydney estão entre as cinco melhores cidades do mundo para universitários. 0 visto australiano permite trabalhar tempo parcial durante os estudos e há grande incentivo ao equilíbrio entre trabalho e lazer.

Cabe mencionar que, diante da necessidade de diversificação do modelo universitário australiano, da real necessidade de competir globalmente e de angariar outras fontes de recursos que não somente as públicas, a estrutura administrativa das instituições de ensino superior sofreu alteração, de forma a melhor gerir os recursos. "Modificamse igualmente as relações internas entre unidades, departamentos acadêmicos [...] seguindo os moldes que os princípios de mercado impõem às relações entre instituições, governos e o campo empresarial" (SGUISSARDI et al., 2005, p. 20).

\section{Quadro 1-Classificação das universidades australianas parceiras do CsF}

\begin{tabular}{|l|l|c|c|c|}
\hline \multirow{4}{*}{ Grupo } & \multicolumn{1}{|c|}{ Universidades } & $\begin{array}{c}\text { The Times } \\
\text { Higher } \\
\text { Education }\end{array}$ & $\begin{array}{c}\text { QS Top } \\
\text { Universities }\end{array}$ & $\begin{array}{c}\text { ARWU } \\
\text { Shanghai } \\
\text { Academic }\end{array}$ \\
\hline \multirow{4}{*}{ Go8 } & University of Melbourne & 33 & 42 & 44 \\
\cline { 2 - 5 } & Australian National University & 52 & 19 & 77 \\
\cline { 2 - 5 } & University of Sydney & 56 & 45 & $101-150$ \\
\cline { 2 - 6 } & University of Queensland & 60 & 46 & 77 \\
\cline { 2 - 6 } & Monash University & 73 & 67 & $101-150$ \\
\cline { 2 - 6 } & University of NSW & 82 & 46 & $101-150$ \\
\cline { 2 - 6 } & University of Western Australia & 109 & 98 & 87 \\
\cline { 2 - 6 } & University of Adelaide & 149 & 113 & $151-200$ \\
\hline \multirow{4}{*}{ ATN } & $\begin{array}{l}\text { Queensland University of } \\
\text { Technology }\end{array}$ & $251-300$ & 263 & $401-500$ \\
\cline { 2 - 6 } & $\begin{array}{l}\text { University of Technology of } \\
\text { Sydney }\end{array}$ & $201-250$ & 218 & $301-400$ \\
\cline { 2 - 6 } & University of South Australia & $351-400$ & 288 & N/A \\
\cline { 2 - 6 } & RMIT University & $401-500$ & 273 & N/A \\
\hline & Curtin University & $401-500$ & 284 & $201-300$ \\
\hline
\end{tabular}

Fonte: elaboração própria com base em dados da Australian Education Network. 
No âmbito do CsF, dois acordos foram assinados com a Austrália. O primeiro deles foi com o Group of Eight(Go8), do qual fazem parte oito universidades de pesquisa. O Go8 preocupa-se com a construção de redes nacionais e internacionais, na busca de soluções para os problemas que assolam a Austrália e também outros países do mundo. O segundo acordo foi assinado com a Australian Tecnhology Network(ATN). Trata-se de uma aliança de cinco universidades de tecnologia focadas na pesquisa aplicada às demandas da indústria e do governo. O Go8 e a ATN são representadas no Brasil pelo Latino Australia Education e a Australian Centre, respectivamente, que fazem a colocação dos estudantes nas universidades.

Do total de 73.353 bolsas implementadas no CsF na modalidade graduação sanduíche (SWG), 6.583 (9\%) foram para a Austrália (CNPq, 2016). Este número refere-se ao total de bolsas implantadas pela Capes e pelo CNPq. As agências dividiram os países participantes do programa, em prol do melhor gerenciamento do elevado número de bolsas. As chamadas públicas realizadas para a Austrália ficaram na gestão do CNPq. Mas existem estudantes nesse país enviados pela Capes devido à transferência de candidatura entre países.

As figuras a seguir mostram a evolução das chamadas públicas realizadas para a Austrália pelo CNPq, os números de estudantes que ingressaram em cursos de inglês e graduação sanduíche, área de interesse e outras informações. Desde o início do programa, foram realizadas dez chamadas públicas SWG. Os estudantes puderam fazer até seis meses de inglês, a depender da proficiência no idioma, seguidos de 12 meses de SWG, incluindo dois ou três meses de estágio em empresa e/ou laboratório de pesquisa. 
Figura 1 - Bolsas implementadas entre 2012 e 2015

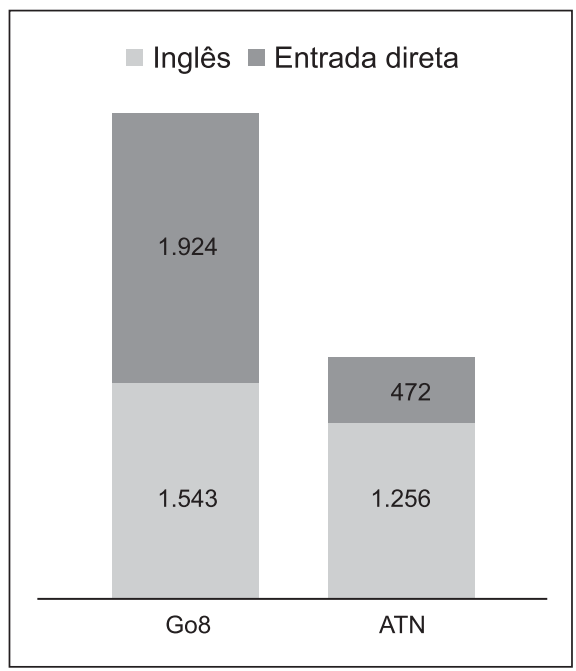

Fonte: elaboração própria com base em dados da Latino Australia Education e da Australian Centre.

Os estudantes do CsF com a proficiência no idioma inglês exigida pelas universidades australianas entram diretamente no programa study abroad (que é classificado como Other Non AQF Award, por não estar entre as qualificações do AQF). Nesse programa, o estudante pode estudar até 12 meses na graduação, sem prejudicar a vida acadêmica, uma vez que os créditos devem ser aproveitados no Brasil. Os estudantes que não têm proficiência em inglês para entrada direta no study abroad, mas que comprovam exames de IELTS ou TOEFL iBT com pelo menos 5.0/35, fazem até seis meses de curso de inglês antes de ingressarem na universidade. Os cursos de inglês se enquadram na categoria ELICOS (English Language Intensive Courses for Overseas Students). 
Figura 2 - Evolução das bolsas implementadas por chamada inglês $\mathbf{x}$ entrada direta

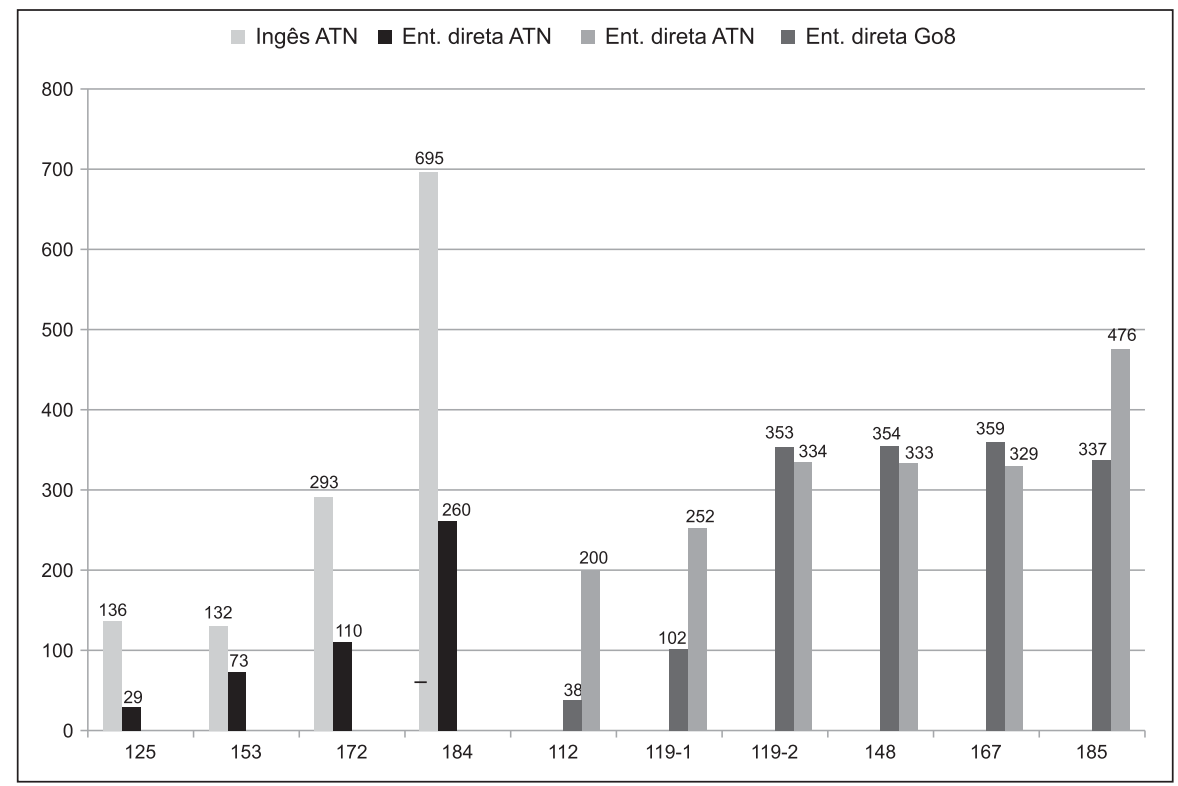

Fonte: elaboração própria com base em dados da Latino Australia Education e da Australian Centre.

A Figura 1 mostra que, do total de 5.195 bolsas, 2.396 foram para estudantes que iniciaram a mobilidade diretamente no study abroade 2.799 para os que precisaram de até seis meses de curso de inglês antes de ingressarem nas universidades. Na Figura 2, é possivel analisar os números por chamada publicada. Os estudantes puderam escolher a universidade de destino, a qual avaliou o currículo e a área de interesse. No Go8, há maior equilíbrio entre estudantes que iniciaram com o curso de inglês e os que entraram no study abroad.

Notadamente, as universidades do Go8 são as que estão mais bem colocadas nas classificações internacionais (Quadro 1). É possível inferir que os estudantes que escolheram as universidades do Go8 possuem maior proficiência no idioma inglês. Estes estão melhor preparados para enfrentar um dos maiores desafios do CsF, que é a barreira linguística. Nas chamadas para a ATN (Chamadas 125 a 184), 0 número de estudantes que iniciaram a mobilidade com curso de inglês é crescente. Ou seja, quanto melhor a proficiência no idioma inglês, maior é a chance de alocação nas melhores universidades. 
Figura 3 - Go8: Distribuição das bolsas implementadas por chamada versus universidades

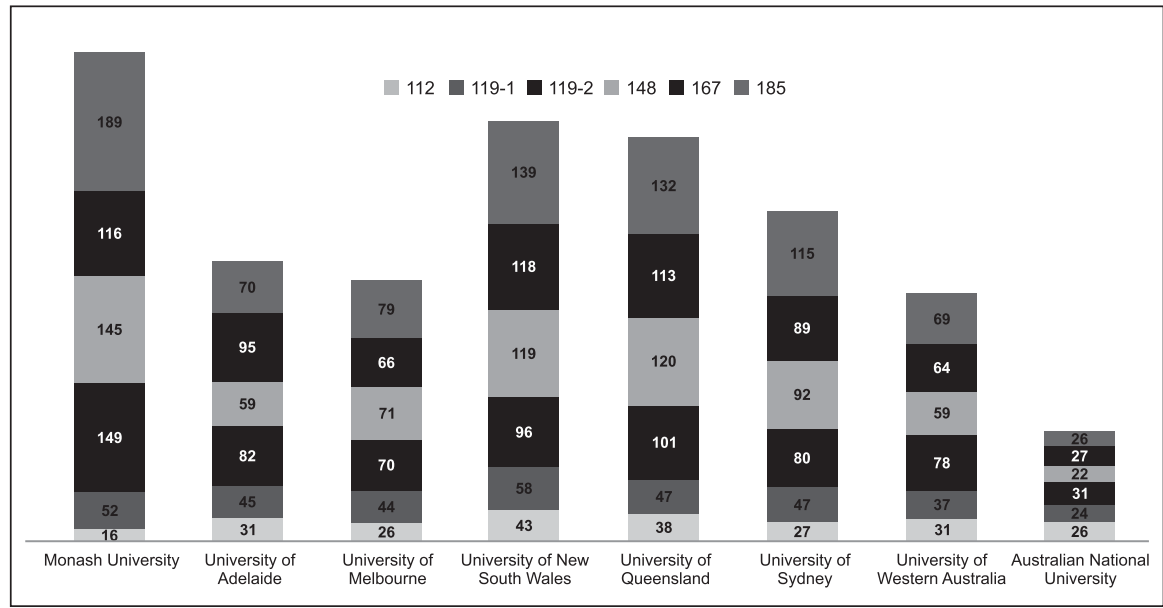

Fonte: elaboração própria com base em dados da Latino Australia Education.

O calendário acadêmico australiano segue o Hemisfério Sul. A primeira entrada de estudantes do CsF ocorreu em julho de 2012 (Chamada SWG CNPq/Capes/Go8 112/2012), sendo que as últimas ocorreram no decorrer de 2015 (Chamada SWG CNPq/Capes/ATN/2014; Chamada SWG CNPq/Capes/Go8 185/2014), a depender dos meses de curso de inglês necessários.

Figura 4 - Go8: Tendência de recepção de estudantes versus universidades

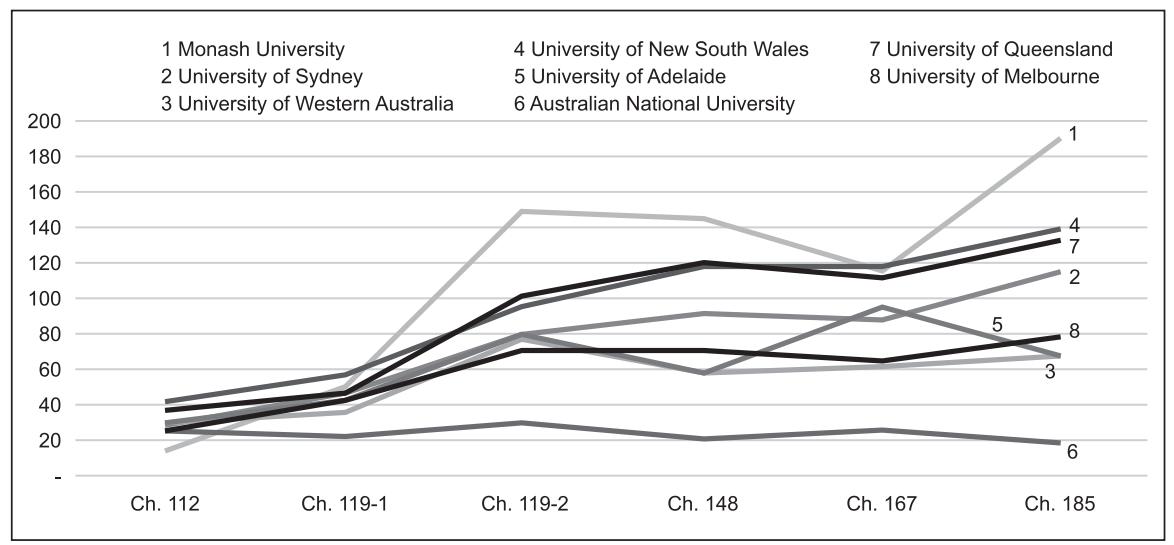

Fonte: elaboração própria com base em dados da Latino Australia Education. 
Figura 5-Go8: Distribuição das bolsas implementadas por universidade inglês versus entrada direta

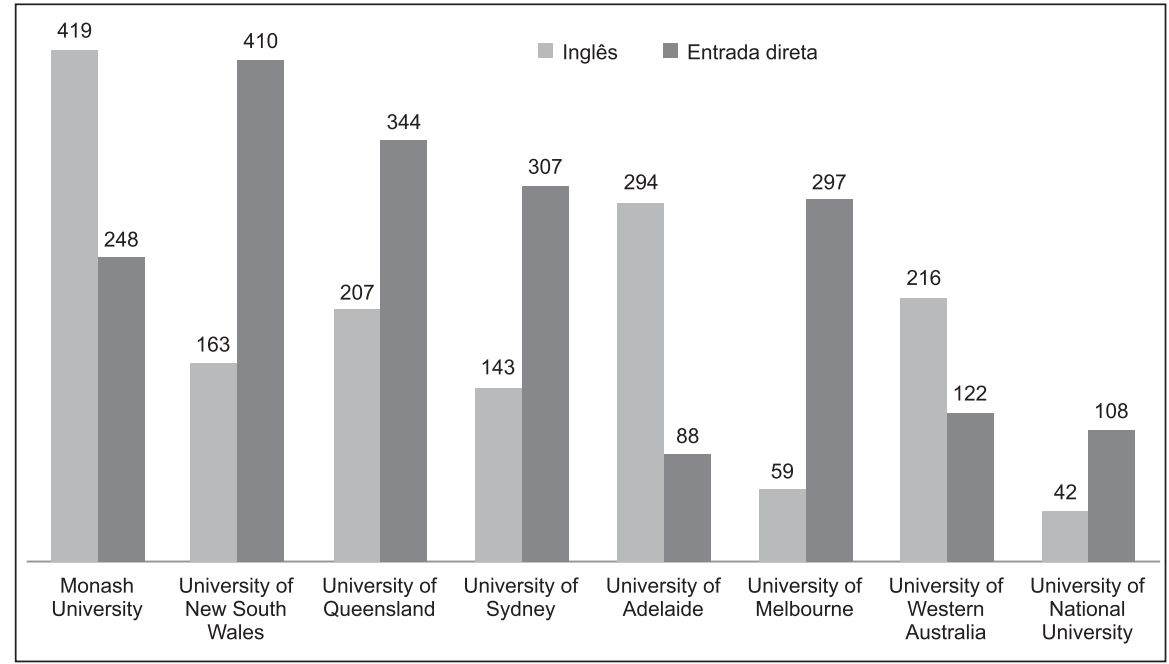

Fonte: elaboração própria com base em dados da Latino Australia Education.

A Australian National University é a mais bem colocada nas classificações e a que possui menos estudantes do CsF. A Monash University é a que mais possui estudantes CsF (Figura 3). A Figura 4 ilustra a tendência de recepção de estudantes pelas universidades do Go8. Uma das críticas feitas ao programa se refere à predominância de estudantes alocados em instituições que não estão entre as melhores do mundo. No caso australiano, 67\% dos estudantes foram alocados nas universidades do Go8. Estas universidades, além de ocuparem as melhores posições nas classificações do Quadro 1, possuem mais estudantes que iniciaram a mobilidade diretamente no study abroad (Figura 5). 
Figura 6 - Áreas prioritárias CsF na Austrália

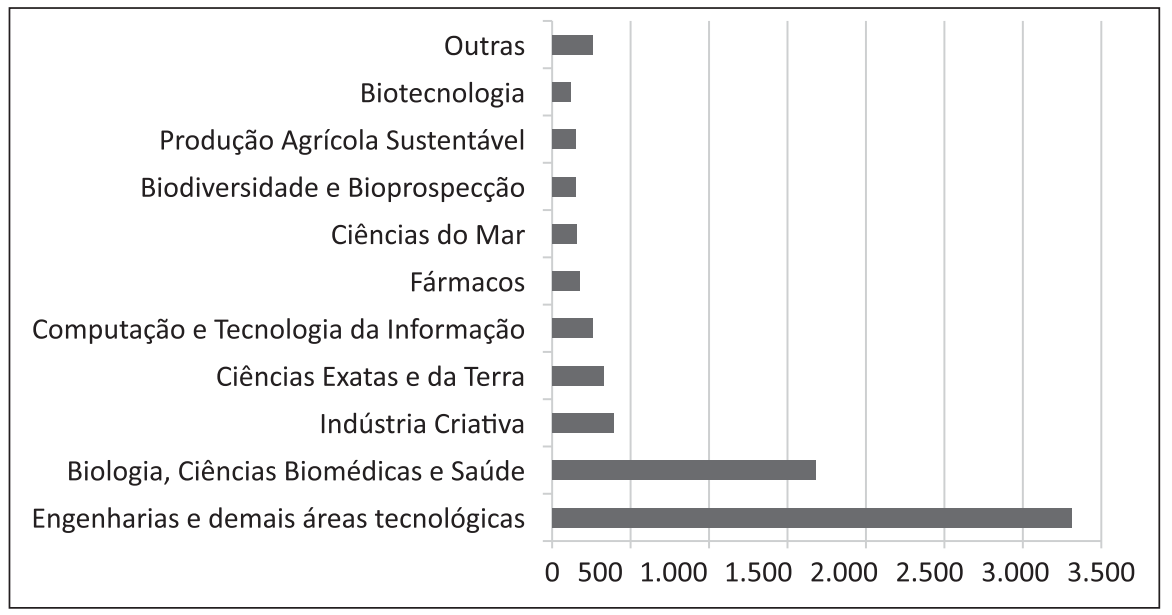

Nota: inclui todas as modalidades de bolsas implementadas no CsF (CNPq, Capes). A graduação equivale a $93 \%$ do total de bolsas. Fonte: elaboração própria com base em dados do CNPq, 2016.

A Figura 6 mostra as principais áreas de conhecimento dos estudantes CsF na Austrália. Os graduandos das engenharias e demais áreas tecnológicas são os que preferem as universidades australianas, o que vai ao encontro dos objetivos do CsF. O Brasil é o sexto país que mais enviou estudantes internacionais à Austrália em 2015, atrás da China, Índia, Vietnam, Coreia do Sul e Malásia (AUSTRALIA, 2016a). Há uma pequena diferença entre a proporção de homens e mulheres $(47,8 \%$ e $52,2 \%$, respectivamente), sendo que a maioria tem entre 20 e 24 anos (AUSTRALIA, 2015d).

Figura 7 - Distribuição dos estudantes brasileiros na Austrália 20112015

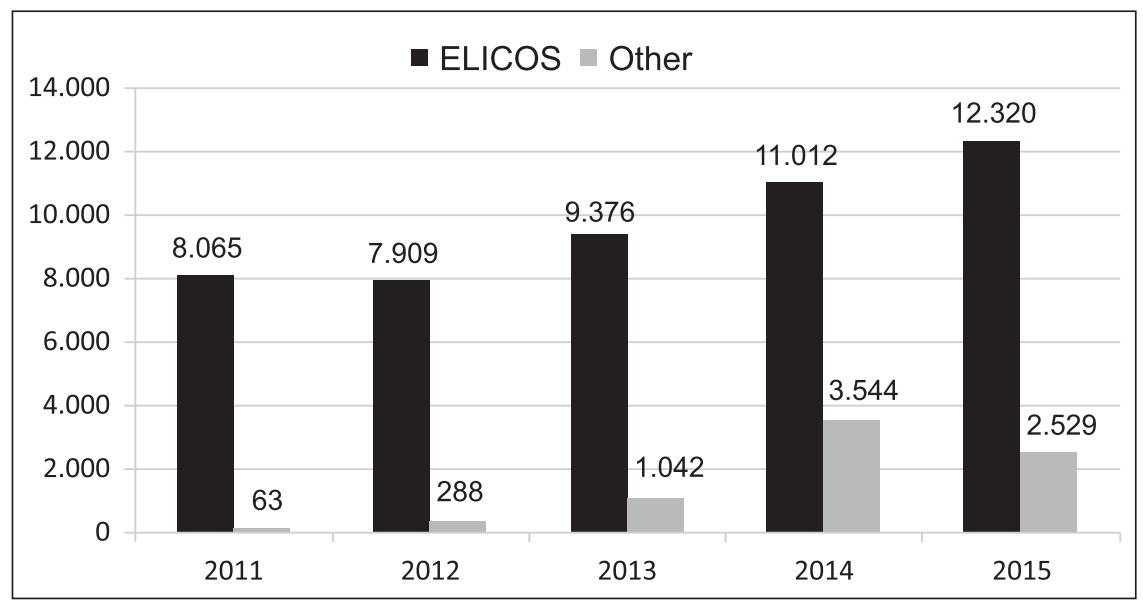

Fonte: elaboração própria com base em dados da International Student Data by Nationality - Brazil. 
A Figura 7 mostra a evolução no número de estudantes brasileiros que escolheram a Austrália para estudar entre 2011 e 2015. A procura pelo ELICOS é consideravelmente maior. Entretanto, após a criação do CsF, há crescimento exponencial em Other, que incorpora os estudantes que ingressam direto no study abroad.

Figura 8 - Impacto do CsF nos totais de estudantes brasileiros na Austrália 2014-2015

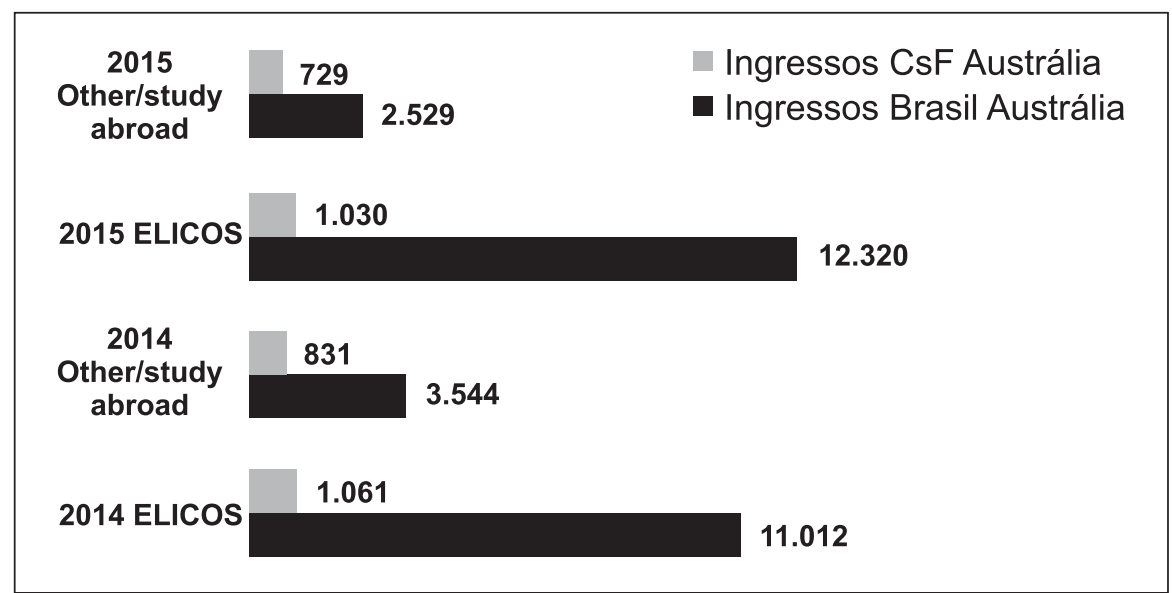

Fonte: elaboração própria com base em dados da Latino Australia Education, da Australian Centre e da International Student Data by Nationality - Brazil.

Mais da metade dos brasileiros que estudam na Austrália estão matriculados em cursos de inglês. A Figura 8 mostra que a contribuição dos ingressos pelo CsF nesses cursos não é grande. No study abroad, há mais ingressos pelo CsF, o que é explicado pelo processo de seleção mais rígido estabelecido pelas universidades australianas. Entretanto, o impacto poderia ser maior, haja vista o fato de que os estudantes, após o período de curso de inglês, ingressam no study abroad. Entretanto, os estudantes são contabilizados como ELICOS, de acordo com o International Student Data by Nationality (AUSTRALIA, 2015c). O Brasil ocupa o $2^{\circ}$ lugar no total de ingressos de estudantes internacionais na Austrália na categoria Other Non AQF Award, após os Estados Unidos (AUSTRALIA, 2015e). 


\section{RESULTADOS DA AVALIAÇÃO DA COMISSÃO DE CIÊNCIA, TECNOLOGIA, INOVAÇÃO, COMUNICAÇÃO E INFORMÁTICA (CCT) DO SENADO FEDERAL}

A CCT, presidida pelo Senador Cristovam Buarque, do Distrito Federal, elegeu como política pública para avaliação em 2015 o tema "Formação de Recursos Humanos, com especial enfoque para o programa Ciência sem Fronteiras". Tornou-se relevante avaliar aspectos positivos e negativos do CsF, em prol do incentivo cada vez mais necessário às ações que preconizem a capacitação de recursos humanos em ciência, tecnologia e inovação.

É importante ressaltar que, apesar de o processo de avaliação realizado pela CCT ter englobado todas as modalidades de bolsas e todos os países destino do CsF, os resultados e recomendações se aplicam ao estudo de caso realizado nesta pesquisa, a saber, o envio de estudantes para Austrália. Do total de 14.627 respondentes da pesquisa, 998 foram para a Oceania, sendo a maioria das bolsas implementadas para a Austrália.

Acrescenta-se que um dos autores deste artigo participou de duas missões ao país. A primeira, em 2012, para compor delegação brasileira de educação superior, e a segunda, em 2015, para participar de intercâmbio científico. Nas duas ocasiões, foi possível observar, mediante visitas às universidades do Go8 e da ATN e a órgãos do governo, o desenvolvimento, as dificuldades e acertos do CsF, o que serviu de subsídio para análises e comparações no estudo aqui apresentado.

O processo de avaliação visou à busca de soluções para as falhas existentes e a apresentação de recomendações em direção ao aperfeiçoamento do CsF, de modo que o programa pudesse ser continuado sem cortes orçamentários. A metodologia compreendeu: análise de informações publicadas e concedidas pelos atores envolvidos no processo, tais como Capes e CNPq; coleta de dados de ex-bolsistas e bolsistas; realização de três audiências públicas, com a participação destes e de outros atores da comunidade científica, como algumas universidades públicas federais e estaduais, o Centro de Gestão e Estudos Estratégicos (CGEE), a Academia Brasileira de Ciências (ABC) e a 
Sociedade Brasileira para o Progresso da Ciência (SBPC); e parceria com o DataSenado e a Consultoria de Orçamentos, Fiscalização e Controle do Senado Federal (Conorf).

O relatório final, $n^{\circ}$ 21/2105, foi apresentado pelo Senador gaúcho

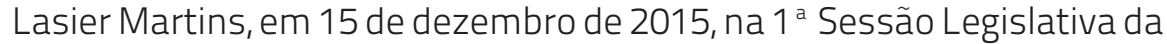

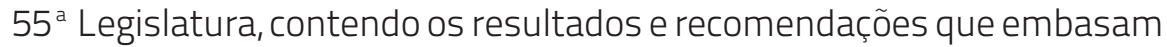
o Projeto de Lei n 798, de 2015, em tramitação no Senado Federal. Sobre as falhas apresentadas, citam-se as que não foram passiveis de solução no curto prazo, entre elas, a pouca ou nenhuma participação das IES de origem na escolha das disciplinas e nas negociações dos acordos; a maior parte das bolsas na modalidade SWG; a falta de atrativos aos pesquisadores estrangeiros e os entraves burocráticos para sua legalização no Brasil; reduzido número de estudantes nas melhores universidades do mundo, o que não se aplica ao caso australiano, uma vez que 67\% dos bolsistas foram alocados nas melhores universidades, conforme mencionado anteriormente; a concentração de estudantes em alguns países; a falta de orientação para envio de relatório técnico; a baixa participação da iniciativa privada; e a concessão de bolsas a estudantes provenientes de famílias com poder aquisitivo elevado.

A propósito, de acordo com as metas do programa, se as bolsas de SWG superaram as metas em $14 \%$, as de doutorado pleno ficaram aquém do desejado em 25,5\% (CNPq, 2016). De fato, esperavam-se mais candidatos qualificados às bolsas de pós-graduação, as quais poderiam ter sido ofertadas mediante melhor planejamento do programa. Entretanto, a CCT acredita que o programa possui mérito no sentido de ter projetado o país internacionalmente e criado oportunidades para ampliação da competência técnico-científica do país.

Sublinhe-se ainda que foram inúmeras as visitas de grupos estrangeiros, instituições de ensino e pesquisadores ao Brasil entre 2012 e 2015. Como exemplo, a Austrália promoveu seminários internacionais com a presença de pesquisadores brasileiros e australianos. A intenção foi a de aproximar os países, na busca de soluções para os problemas que possuem e que, em alguns casos, são semelhantes. 
As recomendações para a segunda fase do programa são:

- Dar continuidade ao CsF;

- Transformar o CsF em política pública;

- Diversificar as fontes de financiamento, por meio de parcerias com o setor privado;

- Priorizar a pós-graduação;

- Facilitar a comunicação entre universidades de origem e de destino;

- Fazer prevalecer os critérios de equidade, sem deixar de fora os melhores estudantes;

- Viabilizar, dentro das possibilidades, programas de financiamentos voltados aos estudantes de melhor nível socioeconômico;

- Atrair mais professores e pesquisadores internacionais ao Brasil;

- Reduzir a burocracia inerente à instalação de professores e pesquisadores internacionais no Brasil;

- Aumentar o envio de estudantes para as melhores universidades do mundo;

- Capacitar as agências e universidades para a elaboração dos projetos de pesquisa;

- Intensificar o apoio acadêmico e emocional oferecido aos estudantes;

- Intensificar o acompanhamento na escolha das atividades acadêmicas que serão cursadas no exterior;

- Corrigir impedimentos que levem ao não reconhecimento de créditos;

- Promover avaliações quantitativas e qualitativas do programa;

- Estimular a avaliação dos resultados do programa pelas universidades;

- Intensificar o investimento público e privado, com vistas à inovação dos laboratórios de pesquisa das instituições brasileiras (BRASIL, 2015b).

Estas recomendações chegaram em momento oportuno. Em 25 de junho de 2014, a Presidência da República lançou o Ciência sem Fronteiras 2.0, com início a partir de 2015, no segundo mandato de Dilma 
Rousseff. No entanto, diante dos últimos acontecimentos políticos e econômicos que assolam o Brasil, até o presente momento, nenhuma nova chamada pública foi lançada para oferta de bolsas SWG.

Sendo uma das etapas do processo avaliativo, a pesquisa de opinião realizada entre os dias $1^{\circ}$ e 28 de setembro de 2015 pelo DataSenado de forma on-line(BRASIL, 2015c) compreendeu as principais vertentes. De uma população de 82.229 bolsistas e ex-bolsistas (26\% bolsistas e $74 \%$ ex-bolsistas) de todas as modalidades de bolsa, apenas $18 \%$ retornaram à pesquisa por e-mail.

Apesar de o índice de respondentes ser baixo, o processo de avaliação proposto e realizado pela CCT foi importante por ter divulgado os primeiros resultados oficiais do CsF. Entre os mais relevantes, menciona-se a experiência de fazer mobilidade internacional avaliada como ótima para 85\% dos respondentes; a satisfação dos estudantes com o programa, em que 48\% estão muito satisfeitos e $44 \%$ satisfeitos; e, a qualidade do curso realizado no exterior, com a maioria das respostas variando de 'Ótimo' (54\%) a 'Bom' (30\%). O interesse por pesquisa aumentou para $57 \%$ dos bolsistas, e 58\% tornaram-se fluentes no idioma do país de destino.

Os resultados são de real importância para análise do alcance das metas do CsF, em especial quando 67\% dos ex-bolsistas declararam manter ativa a rede acadêmica, 68\% conseguiram multiplicar os conhecimentos adquiridos fora no Brasil e 53\% afirmaram se dedicar mais aos estudos após o período de mobilidade acadêmica. Acrescentase que 53\% dos respondentes querem trabalhar no Brasil, o que chama a atenção para a necessidade de se estabelecer ambiente profissional inovador e competitivo para a permanência dos ex-bolsistas do programa.

\section{CONSIDERAÇÕES FINAIS}

Não resta dúvida de que o CsF foi uma política do governo Dilma Rousseff para alavancar o desenvolvimento do Brasil por meio 
da capacitação de estudantes e pesquisadores no exterior. De forma passiva, o Brasil enviou estudantes para fora do país como jamais o fizera em sua história, o que projetou a ciência e a educação brasileiras internacionalmente. Esse movimento pode ser considerado como exceção entre os países semiperiféricos, ao se tratar de políticas de internacionalização, ainda que temporária.

É certo que muitas críticas têm sido feitas, destacando-se, entre elas, a da SBPC, sobre o uso do Fundo Nacional de Desenvolvimento Científico e Tecnológico (FNDCT) como recurso principal do programa. O fundo foi criado para fomentar a pesquisa, o desenvolvimento e a inovação, que ficam prejudicados. Com efeito, a presidente da SBPC, Helena Nader, afirmou ao Jornal da Ciência que o CsF está "depauperando o FNDCT, que não foi criado para isso", apesar de elogiar o programa (apud MONTEIRO, 2016). Outra preocupação partiu de Cláudio de Moura Castro e outros e é referente às bolsas de curta duração do tipo "sanduíche", que, pela falta de planejamento, juntamente com a ênfase nas concessões, podem não trazer benefícios sólidos (2012, p. 32).

Em que pesem essas críticas, é consenso que a mobilidade acadêmica é capaz de mudar a vida de quem a usufrui, por meio da capacitação educacional, intercultural, profissional e pessoal (DWYER; PETER, 2008 apud MURRAY et al., 2011, p. 23). Nesse sentido, o CsF veio para oportunizar aos brasileiros de todas as classes sociais uma das melhores experiências de vida, com impactos duradouros.

Apesar de sua relevância, dos aspectos positivos e das recomendações feitas pela CCT, que sugeriu a continuidade do CsF, algumas ponderações precisam ser feitas caso o cenário político econômico do país permita a continuidade do programa. Entre as sugestões, chama-se a atenção para a prioridade à pós-graduação. O programa concentrou-se excessivamente em bolsas de graduação sanduíche. É fundamental ampliar as bolsas de pós-doutoramento em áreas estratégicas e em instituições estrangeiras reconhecidas internacionalmente.

Sobre esse aspecto, os gestores da política científica e tecnológica da Austrália, em diversos depoimentos colhidos na ocasião das missões, 
salientaram a importância da cooperação científica concentrada na pós-graduação, o que coincide com as críticas apontadas. Do total de bolsas implementadas para a Austrália, apenas 7,5\% foram para a pósgraduação (CNPQ, 2016). O país tem algumas das melhores universidades do mundo, que o ajudaram a lograr 15 Prêmios Nobel e que devem ser consideradas quando se pretende priorizar a pós-graduação.

Outra recomendação da CCT foi a de aumentar a presença de estudantes nas melhores universidades estrangeiras. Essa sugestão é importante, pois nem sempre os estudantes brasileiros foram direcionados para as melhores universidades. Vale ressaltar que o modelo australiano é exemplo a ser seguido, uma vez que foi capaz de absorver dois terços dos estudantes nas melhores universidades locais, certamente, devido aos critérios mais rígidos na seleção.

Nessa mesma linha, insere-se a recomendação de atrair pesquisadores estrangeiros que possam contribuir para o desenvolvimento científico e tecnológico nacional. O programa pouco avançou nessa direção. As leis brasileiras necessitam de revisão, no sentido de facilitar a entrada de pesquisadores, assim como os laboratórios e universidades devem ser internacionalizados o suficiente para recebê-los. Isso feito, não será muito difícil conquistar também os egressos do CsF, para que permaneçam no país em condições favoráveis de estudo, pesquisa e trabalho.

Os primeiros resultados proporcionados pela avaliação do programa pela CCT foram positivos, a ponto de subsidiar a recomendação de transformá-lo em política pública. Afinal, os ganhos para a internacionalização da educação superior entre 2011 e 2015 foram consideráveis. O número de ex-bolsistas que mantêm a rede de contato estabelecida no exterior é significativo. Este fato pode vir a intensificar a cooperação técnico-científica entre o Brasil e outros países. As redes podem ser usadas em benefício local, promovendo a mobilidade nacional de conhecimento, com a participação das universidades e instituições de ensino brasileiras.

Ressalte-se que as últimas visitas de instituições de pesquisa australianas ao Brasil estiveram focadas na pós-graduação e nas 
parcerias técnico-científicas entre os dois países. Estas têm avançado, haja vista os últimos acordos de cooperação assinados com instituições voltadas à pesquisa, como a Fundação Araucária e a Fundação de Amparo à Pesquisa do Estado de São Paulo (Fapesp), para não mencionar outras.

A antecipação do contato de estudantes com a pesquisa ainda na graduação pode ter ofuscado a pós-graduação num primeiro momento, uma vez que a maioria das bolsas no CsF foi concedida à graduação. Mas esses estudantes são os candidatos em potencial às bolsas de pós-graduação no curto prazo, com a vantagem de estarem mais amadurecidos. Isto pode resultar no aumento de publicações conjuntas e também em pesquisa patenteada.

Em suma, é um desafio na atual conjuntura política e econômica do Brasil. Entretanto, a educação, a ciência e a tecnologia não deveriam transitar nas listas de cortes orçamentários. As recomendações propostas pela CCT, seja a de diversificar as fontes de financiamento, seja a de intensificar o investimento público e privado, são soluções em prol da continuidade do CsF 2.0 e do desenvolvimento do país. Há urgente necessidade de que a política de ciência e tecnologia evolua para o status de política pública e, assim, reste menos sujeita a oscilações do mundo político e econômico.

\section{Referências}

AUSTRALIA. Australian Government. Department of Education and Training. Country Education Profiles. Australia, 2015a. 76 p. Disponível em: <https://internationaleducation.gov.au/Documents/ED15-0091_ INT_Australia_Country_Education_Profile_2015_ACC.pdf>. Acesso em: 9 mar. 2016.

. Australian Government. Department of Education and Training. Draft National Strategy for International Education. For consultation. April 2015b. 87 p. Disponivel em: <https://internationaleducation. gov.au/International-network/Australia/InternationalStrategy/ 
Documents/Draft\%20National\%20Strategy\%20for\%20International\%20 Education.pdf>. Acesso em: 9 mar. 2016.

. Australian University Rankings. Australian Education Network. Disponivel em:<http://www.australianuniversities.com.au/rankings/>. Acesso em: 10 mar. 2016.

. Export income to Australia from international education activity in 2013-14. Research Snapshot, Nov. 2014. Disponivel em: <https://internationaleducation.gov.au/research/ResearchSnapshots/Documents/Export\%2OIncome\%20FY2013-14.pdf>. Acesso em: 9 mar. 2016.

International student data by nationality Brazil. 2015c. Disponivel em: <https://internationaleducation.gov.au/research/ international-student-data/pages/default.aspx>. Acesso em: 16 dez. 2015.

. International student number 2014. Research Snapshot, Mar. 2015d. Disponivel em: <https://internationaleducation.gov. au/research/Research-Snapshots/Documents/International\%20 Student\%20Numbers\%202014.pdf>. Acesso em: 16 dez. 2015.

. International students studying non-award courses. Research Snapshot, Aug. 2015e. Disponivel em: <https://internationaleducation. gov.au/research/Research-Snapshots/Documents/International\%20 Students\%20studying\%20non-award\%20courses.pdf>. Acesso em: 14 dez. 2015.

. Record numbers of international students choose Australia. Media Release, Feb. 2016. Disponivel em: <https:/ / ministers.education. gov.au/colbeck/record-numbers-international-students-chooseaustralia>. Acesso em: 28 mar. 2016.

AUSTRALIAN CENTER. Dados Gerais CsF ATN 2011-2015 [mensagem pessoal]. Mensagem recebida por <dileine.cunha@cnpq.br> em 23 fev. 2016. 
AVEIRO, T. M. M. O Programa Ciência sem Fronteiras como ferramenta de acesso à mobilidade internacional. Tear: Revista de Ciência e Tecnologia, Canoas, v. 3, n. 2, 2014. Disponivel em: <http://seer.canoas.ifrs.edu.br/ seer/index.php/tear/article/view/213>. Acesso em: 16 fev. 2016.

BANCO MUNDIAL. Higher Education: The Lessons of Experience. Washington, 1994. Disponivel em: < http://www-wds.worldbank.org/ external/default/WDSContentServer/WDSP/IB/2000/07/19/00000 9265_3970128113653/Rendered/PDF/multi_page.pdf>. Acesso em: 16 fev. 2016.

BRADLEY, D. et al. Review of Australian Higher Education - Final Report. Canberra: DEEWR, 2008. 271 p. Disponivel em: <http:/ / www.voced.edu. au/content/ngv\%3A32134>. Acesso em: 9 mar. 2016.

BRASIL. Ministério da Ciência, Tecnologia e Inovação. Estratégia Nacional de Ciência, Tecnologia e Inovação 2012-2015. Balanço das Atividades Estruturantes 2011. Brasília: MCTI, 2012. Disponivel em: <http:/ /www. mct.gov.br/upd_blob/0218/218981.pdf>. Acesso em: 9 mar. 2016.

Senado Federal. Pesquisa de Opinião: Avaliação do Programa Ciência sem Fronteiras. Brasília, out. 2015a. Disponível em: < https://www12.senado.leg.br/institucional/datasenado/pdf/ RelatrioDataSenado_CinciasemFronteiras.pdf >. Acesso em: 9 mar. 2016.

Relatório n 21/2015-CCT. Brasília, 15 dez. 2015b. Disponível em:<http://legis.senado.leg.br/mateweb/arquivos/mate-pdf/185018. pdf>. Acesso em: 9 mar. 2016.

. Requerimento $\mathrm{n}^{\circ}$ 4/2015-CCT. Brasília, 10 mar. 2015c. Disponivel em: <https://www25.senado.leg.br/web/atividade/materias/-/ materia/119979/pdf>. Acesso em: 9 mar. 2016.

CAPES - Coordenação de Aperfeiçoamento de Pessoal de Nível Superior. Plano Nacional de Pós-Graduação: PNPG 2011-2020. Brasília: Capes, 2010. v. 1. 309p. 
CASTRO, C. de et al. Cem Mil Bolsistas no Exterior. Interesse Nacional, São Paulo, ano 5, n. 17, p. 25-36, abr./jun. 2012. Disponível em: <http:/ / www.schwartzman.org.br/simon/cemmil.pdf>. Acesso em: 16 fev. 2016.

CNPQ - Conselho Nacional de Desenvolvimento Científico e Tecnológico. Ciência sem Fronteiras. Disponivel em: <http://www. cienciasemfronteiras.gov.br/web/csf>. Acesso em: 18 fev. 2016.

DWYER, M.; PETER, C. The benefits of study abroad: new study confirms significant gains. Disponível em: <http://www.iesabroad.org/studyabroad/news/benefits-study-abroad\#sthash.gZwlpOGx.dpbs>. Acesso em: 10 mar. 2016.

KEOHANE, R.; NYE, J. Power and Interdependence. New York: Longman, 2001.

KNIGHT, Jane. Modèle d'internationalisation ou comment faire face aux réalités et enjeux nouveaux. In: OCDE. L'enseignement supérieur en Amérique latine - la dimension internationale. Paris: OCDE, 2005, p.11-45.

LATINO AUSTRALIAN EDUCATION. Chamadas Go8 2011-2015[mensagem pessoal]. Mensagem recebida por <dileine.cunha@cnpq.br> em 23 fev. 2016.

LIMA, M. C.; CONTEL, F. B. Educação Superior na Austrália: a expressão do capitalismo acadêmico. In: . (Org.) Internacionalização da Educação Superior: Nações ativas, nações passivas e a geopolítica do conhecimento. São Paulo: Alameda Editorial, 2011. p. 357-392.

LIMA, M. C.; MARANHÃO, C. M. S. de A. O sistema de Educação Superior Mundial: entre a internacionalização ativa e passiva. Avaliação-Revista da Avaliação da Educação Superior, Sorocaba, SP, v. 14, n. 3, p. 583-610, nov. 2009. Disponivel em: <http://www.scielo.br/pdf/aval/v14n3/ a04v14n3.pdf>. Acesso em: 9 fev. 2016.

MEEK, V. L. Produção do Conhecimento na Educação Superior Australiana: do acadêmico ao comercial? Educ. Soc., Campinas, v. 25, n. 88, p. 1023- 
1043, Especial, out. 2004. Disponivel em: <http:/ /www.scielo.br/scielo. php?script=sci_arttext\&pid=S0101-73302004000300018 . Acesso em: 9 fev. 2016.

MERLE, J.; MEEK, L. Scientific mobility and international research networks: trends and policy tools for promoting research excellence and capacity building. Studies in Higher Education - SRHE, London, v. 38, n. 3, p. 331-344, March 2013. Disponivel em: <https:/ / www.researchgate. net/publication/263602442_Scientific_mobility_and_international_ research_networks_Trends_and_policy_tools_for_promoting_ research_excellence_and_capacity_building>. Acesso em: 16 fev. 2016.

MONTEIRO, V. Especialistas defendem ajuste do Programa Ciência sem Fronteiras em audiência pública. Jornal da Ciência, Brasília, 30 abr. 2016. Disponivel em: <http://www.sbpcnet.org.br/site/noticias/materias/ detalhe. php?id=3967>. Acesso em: 10 jun. 2016.

MURRAY, D. et al. State of current research in international education. Background paper. Australia: LHMartin Institute, 2011.

PEREIRA, V. M. Arranjos de uma política: uma análise sobre o Programa Ciência sem Fronteiras. Revista NAU Social, Salvador, v. 6, n. 10, p. 103117, maio/out. 2015. Disponivel em: <http:// www.periodicos.adm.ufba. br/index.php/rs/article/view/463>. Acesso em: 5 mar. 2016.

ROCHA NETO, I. Prospectiva da Pós-Graduação no Brasil (2008 - 2022). RBPG, Brasília, v. 7, n. 12, p. 58-79, jul. 2010. Disponivel em: <http:// ojs.rbpg.capes.gov.br/index.php/rbpg/article/view/181>. Acesso em: 5 mar. 2016.

SGUISSARDI, V. Educação Superior no limiar do novo século: Traços internacionais e marcas domésticas. Revista Diálogo Educacional, Curitiba, v. 3, n. 7, p. 121-144, set./ dez. 2002. Disponivel em: <http:/ / www. redalyc.org/pdf/1891/189118078010.pdf>. Acesso em: 9 mar. 2016.

SGUISSARDI, V. et al. Internacionalização, Gestão Democrática e Autonomia Universitária em Questão. Textos para discussão, Brasília, 
n. 20, p. 5-27, 2005. Disponível em: <http://www2.unifap.br/gpcem/ files/2011/09/Autonomia-Universitaria-TEXTO-DISCUSS\%C3\%830N\%C2\%BA-20.pdf>. Acesso em: 5 mar. 2016.

SPEARS, E. O valor de um intercâmbio: mobilidade estudantil brasileira, bilateralismo e internacionalização da educação. Revista Eletrônica de Educação, São Carlos, v. 8, n. 1, p. 151-163, maio 2014. Disponível em: <http://www.reveduc.ufscar.br/index.php/reveduc/article/ viewFile/1026/320>. Acesso em: 5 mar. 2016.

STALLIVIERI, L. Ciência sem Fronteiras abriu diálogo qualificado entre instituições mas escancarou dificuldade dos estudantes de se comunicar em outros idiomas. Ensino Superior Unicamp, Universidade Estadual de Campinas, SP, 24 fev. 2016. Disponível em: <https:/ / www. revistaensinosuperior.gr.unicamp.br/artigos/ciencia-sem-fronteirasabriu-dialogo-qualificado-entre-instituicoes-mas-escancaroudificuldade-dos-estudantes-de-se-comunicar-em-outros-idiomas>. Acesso em: 16 fev. 2016.

UNESCO. Organização das Nações Unidas para a Educação, a Ciência e a Cultura. Institut for Statistics. 2016. Disponivel em: <http:/ / www.uis. unesco.org/Education/Pages/international-student-flow-viz.aspx>. Acesso em: 4 mar. 2016.

WALLERSTEIN, I. Semi-pheriferical countries and the contemporary world crisis. Theory and Society, v. 3, n. 4, p. 461-484, 1976. Disponível em: <http:/ / philpapers.org/rec/WALSCA-4>. Acesso em: 4 mar. 2016.

Recebido em 07/04/2016

Aprovado em 14/06/2016 